\title{
Dreams of disappointment
}

John Maddox

PROFESSOR Victor Jakob, theoretical physicist at a small German university that could be anywhere between Heidelberg and Göttingen, is a creature of the compelling imagination of Professor Russell McCormmach, professor of the history of science at Johns Hopkins University. At the end of his career in 1918, Jakob's spirit has been broken by a succession of disasters - the impending defeat of the Kaiser's reich, his personal defeat and humiliation by the head of the physics institute (an experimentalist), by his sense that the classical values of German society had been corrupted by the synthetic patriotism of the twentieth century and by his failure or, rather, his disinclination to come to grips with quantum physics.

The first appearance on the stage that McCormmach has designed for his protagonist is at a patriotic evening arranged by the university and the local Goethe Society, where he is waiting for the Bach to end to give his first-hand account of heroism in the Franco-Prussian War nearly half a century earlier; before finishing, he collapses with what appears to be a minor stroke. By the end of the book Jakob has sadly wandered off into the woods, fallen into a ditch from which he cannot climb but from which the roar of the guns firing near the university can be heard. Whether the old gentleman succeeds in blowing out his brains with the revolver in his pocket is not known.

In between, McCormmach's Jakob is but a vehicle for a stream of unspoken reminiscence, almost free association, guided chiefly by his wish to understand what has become of himself. The shining hopefulness of his student days had long since drained away. But why had his devotion to classical physics failed to bring the reward of discovery that he and his teachers had every reason, at the outset, to expect? "Why", Jakob keeps worrying, "have I so obviously fallen short of what Hertz, Helmholtz, Drude and those great men expected of me?".

So McCormmach's Jakob is more than a device for telling what physics was like in the early decades of this century. It is also a window on the corrosiveness of disappointment, a way of showing how a person such as Jakob can be destroyed by too great a gap between reality and expectations of himself and of others. McCormmach says that he has "drawn on an approach from fiction' 'but he could as well have said that he has written a novel, and a good one at that.
Night Thoughts of a Classical Physicist. By Russell McCormmach. Pp.215. ISBN 0-674-62460-2. (Harvard University Press: 1982.) $\$ 19.50, £ 10.50$.

Jakob's bemusement with his plight is described best by Anna von Helmholtz's account in 1894 of her husband Hermann towards the end of his life:

It is always as if his soul were far, far away, in a beautiful noble sphere where only science and eternal laws rule - and then that does not correspond to anything which surrounds him and he becomes unclear and confused.

Jakob's failure to make a bridge between his internal picture of what the world is like, and the reality outside, is what destroyed him - though reality itself, Jakob as a Jew and as a theoretician, conspired to that end.

Jakob's night thoughts are a moving account of the personal disappointments of academic life in the traditional German academic institute. At the point in his own young career when the next step would have been an appointment as tenured professor (Ordinarius), several universities informally enquired of him whether he would be free, but none of them translated this into a formal "call" - the firm offer of a job that, even if declined, could then appear in a curriculum vitae. So Jakob soldiered on, becoming indispensable as a teacher (especially when military service dragged away the younger teachers) and was rewarded with the title of honorary professor, an advertisement that he has not quite made the grade.

Before that humiliation, Jakob finds himself being interviewed by the Prussian official Althoff about the prospect of taking over the physical institute in Berlin. Althoff, although only a junior official at the ministry, seems to have established the right to appoint most physics professors at the German universities and to negotiate their terms of service. Among other misdemeanours, he was the principal agent whereby Philip Lenard was foisted on the unwilling faculty at Breslau. Althoff is best known for his complaint that professors are like whores "who go with the one who pays the most". "Each", he is given as saying, "has his price, which is not high".

The account of Jakob's resentment of this interview with the overbearing Althoff is both moving and persuasive, yet it is also one of the points at which McCormmach's technique lets him down. The question why powerful Althoff should be persuading an unsuccessful provincial such as Jakob to take the post occupied by people such as Helmholtz, Hertz and Drude is a stumbling-block. Worse, at this point the notes tucked away at the back of the book turn out to be as gripping as the narrative.

The most compelling part of Jakob's stream of consciousness is his affection for the great men of German physics Helmholtz, Hertz, Drude and so on. The tale has it that Jakob's study is decorated with the portraits of his heroes, among whom Maxwell (whom Jakob had never met) and Helmholtz take precedence. But Drude, appointed director of the Berlin institute in 1905, is Jakob's most vivid recollection. A whirlwind of energy, he sought to reorganize the institute but was enmeshed in the tangled bureaucracy of the state - it took endless letters even to change a light-bulb, according to Jakob so that almost the most tangible of the marks left by Drude on the institute was his habit of keeping his stick of chalk on the left-hand side of the blackboard. Drude himself was driven sick with worry, and to suicide in 1906.

Perhaps predictably, Jakob is better on people than on physics. His stubborn scepticism of the Plancks of his world stems more from aesthetic than from intellectual arguments. He grumbles at the way in which the quantum physicists appear to have been licensed to take any hypothesis as a starting point, making physics seem like mere mathematics. Rather, Jakob argues, just as the study of Latin and Greek is based on the supposed congruence of ancient and modern minds, so classical physics is based on the assumption that at some level there is a congruence between mental and natural processes. But Jakob's refusal to follow Planck, while reinforced by Planck's firm but kind rejection of Jakob's attempt to square the circle of contradiction that had arisen, is at root simply a protest at the way that everything seemed to have changed.

Jakob's stream of reminiscence ends with his fall into the ditch on a hillside high above the university at which his career ended, in the last September of the war. McCormmach, his creator, seems principally concerned to have Jakob describe the social problems of German physics in those stirring days. That his pastiche of a hero should have turned out to be such an appealing down-trodden academic is an uncovenanted benefit, both haunting and memorable.

John Maddox is Editor of Nature. 